It is not long since bactcria and Cyanophyceae wero being classed together because they had no nucleus.

The second defect has been hinted at in my previous quotation from the text, the meaning of which is clear enough, at least on the second reading, but such TeutoAmerican turgor is evident throughout this English version of a book that I presume to have been written originally in German. What, for example, is meant by "While every nucleoid is a coherent structure, tho opposite conclusion is not permissible, at least not on a cytological level" ? If it means the converse conclusion, that every coherent structure is a nucleoid, most of us would agree that it is not permissible, but we hardly need to be admonished on the score. None the less, it is an excellent and well argued text.

The bibliography includes 954 references by 845 authors and these cover a great deal of valuable information that is not readily obtainable in other textbooks.

K. A. Bisset

\section{HEAT MEASUREMENT}

\section{Experimental Thermodynamics}

Vol. 1: Calorimetry of Non-reacting Systems. Edited by John P. McCullough and Donald W. Scott. (Prepared under the sponsorship of the International Union of Pure and Applied Chemistry, Commission on Thermodynamies and Thermochemistry.) Pp. xix +606 . (Butterworths: London, December 1968.) $220 s$.

THIS book is the first of two volumes concerned with the measurement of heat capacity and enthalpies of phase change, and is intended to complement the two previous volumes by Rossini and by Skinner which dealt with the measurement of heats of reaction. The subject matter of these new volumes is further restricted to macroscopic systems, the reader being referred to two more books which cover the field of microcalorimetry.

The approach of this book is similar to that of Rossini and Skinner, beginning with a general introduction followed by a series of chapters, each doaling with particular topics of calorimetry. The introductory chapters, four in number, are, however, more extensive than in tho previous volumes. A detailed account is given of temperature scales and measurements, energy measurement and standardization, followed by a chapter on general design principles of the calorimeter. The first three of these chapters could be read with profit by every physical science undergraduate; although I think that Ginnings in the first chapter should have made it clear that the definition of accuracy in terms of a true quantity is a philosophical and not a scientific criterion.

The contents of the succeeding chapters are: adiabatic low-temperature calorimetry; low-temperature calorimetry with isothermal shield; calorimetry below $20^{\circ} \mathrm{K}$; high-temperature drop calorimetry; adiabatic calorimetry between 300 and $800^{\circ} \mathrm{K}$; vapour-flow calorimetry; calorimetry of saturated fluids; heat capacity of liquids and solutions near room temperature; studies at low temperatures; and high speed thermodynamic measurements. Each chapter follows the same general pattern with details of calorimetric design, procedures, calculations and discussion. The editors have been particularly successful in avoiding overlap, yet each chapter could still be read as a single entity. As might be expected in a work of this kind, each chapter is well ctocumented with a good proportion of recent references, both to primary sources and important reviews and monographs.

As with all IUPAC publications a number of specialists have collaborated in the preparation of this work in an endeavour to present a definitive study. This they have achieved.

\section{COMPRESSED CHEMISTRY}

\section{Foundations of Quantum Chemistry}

By 'T. E. Peacock. Pp. ix +162 . (Wiley: London and New York, December 1968.) 48s.

A NotaBLE feature of this book is that it closely represents the contents of a forty lecture course on quantum chemistry to undergraduates. The honest author has resisted the temptation to expand it to include all those topics he might have done if he had unlimited lecture time. How often have we not envied some authors their near-genius students who accepted, presumably without too much protest, the contents of their one semester or one year course?

This book starts, as seems appropriate for an advanced undergraduate course, with a simple introduction to the basic ideas of quantum mechanies following the modern postulational approach derived from Dirac's work. It assumes a working knowledge of linear algebra and a familiarity with the special functions that arise in quantum mechanics. This introduction is followed by a survey of perturbation theory and the variational method and a chapter on the quantum mechanical treatment of atoms including the vector model and Slater's theory of complex atoms. Alas, the student, after having worked his way through much heavy algebra and corrected the very many printing mistakes, is denied at the very end a statement of how well (or badly) the theory agrees with experiment.

The later chapters represent a more conventional and generally well judged treatment of molecular orbital and valence bond theory with the emphasis on small molecules and the simpler organic systems. The book ends with a very brief and somewhat inadequate chapter on inorganic applications. One presumes that these students were being given a fuller account elsewhere by a modern inorganic chemist.

Compressing this material into 160 pages has meant that some topics have received little more than a bare mention and at times simplicity has encroached upon accuracy. This is to be found in the introductory scction where the basic postulates are not sufficient to fully understand the time varying systems that a student will encounter before long in his career. Signs of hasty preparation are shown by the large number of printing mistakes, the prevalence of carelessly worded statements, the wrong and missing units and sometimes the failure to define new parameters when they are first introduced. Together with the absence of problems or examples for the student to tackle, it makes it difficult to recommend this edition to any but the knowledgeable student seeking a concise summary of the field.

His teachers, however, ought to look at it just to see what is involved in taking the subject beyond the elementary level (as presented, for example, in Coulson's Valence). If the matter is not to be treated superficially the sacrifice of traditional but important chemistry could be considerable. Might not the best place for it be as part of a graduate study programme?

R. J. R. HAYWARD

\section{VERSATILITY IN MATHEMATICS}

Hermann Weyl: Gesammelte Abhandlungen

Edited by K. Chandrasekharan. Band 1: Pp. 698. Band 2: Pp. 647. Band 3: Pp. 791. Band 4: Pp. 694. (Springer-Verlag: Berlin and New York, 1968.) 168 DM; $\$ 42$.

IN this age of specialization, most young scholars grow up with experience gained only in one or two fields of research; contact may be made with neighbouring areas, 